\title{
Gender Differences in the Development of Schizophrenia
}

\author{
Tarasova Sofya ${ }^{1, *}$ Bobrovnikova Anna ${ }^{2}$
}

\author{
${ }^{1}$ Psychological Institute of Russian Academy of Education, Moscow, Russia \\ ${ }^{2}$ Dubna State University, Dubna, Russia \\ *Corresponding author. Email: syutarasov@yandex.ru
}

\begin{abstract}
We conducted a research involving 60 adults with the diagnosis of schizophrenia (F20). The main criterion for analyzing gender differences in schizophrenia development was the trigger mechanism of the disease. We have found out that the trigger for the onset in women is often a psychotraumatic situation associated with unhappy love or sexual experience: rape, attempted rape, "unhappy love" (56\% of cases). As for the factors aggravating premorbid background, eating disorders (37\% of cases) and suicidal behavior (31\% of cases) are the most common among women. In men, the trigger is also associated with a psychotrauma in the sphere of interpersonal relationships (38\% of cases). There are also such aggravating factors as antisocial behavior (18\% of men) and alcohol and drug abuse (50\% of men). As for the sociopsychological parameters of the disease course, higher level of social activity is registered in women. Patients' ability to assess their disorder critically and to orient themselves in their own personalities is characterized by similar rates. $56 \%$ of women demonstrate a relatively critical attitude towards their defective condition. In men, the percentage is $37 \%$. We find the results to be interest enough, and the obtained trends allow us to outline directions for further work. The hypothesis of interrelation between creativity and schizophrenia is supported by the results of the diagnostic work analysis.
\end{abstract}

Keywords: schizophrenia, premorbid personality traits, psychotraumatic situation, gender differences, high abilities

\section{INTRODUCTION}

Schizophrenia is a common mental disorder. Its onset often concurs with the periods of active personal development. Schizophrenia causes social maladjustment of almost $1 \%$ of working age population. One of the most important characteristics of adjustment is the adequate response to the expectations of one's social environment. The level of maladjustment in schizophrenia can vary from mild to severe. There is a wide range of studies on social maladjustment by Russian and foreign authors. The researchers want to understand the peculiarities of the initial period of the disease and to develop the gentlest possible models of medical and psychological assistance. People suffering from schizophrenia often belong to creative occupation category. The discussion of interrelation between talent and mental disorders goes back to the days of Cesare Lombroso [1, 12].

The developers of DSM-5 traditionally consider schizophrenia in dynamics, they speak about the importance of a differentiated psychopathological approach and a reasonable combination of quantitative and qualitative methods in analyzing each case [13]. In order to make a prognosis, it is necessary to describe a particular variation of disease course. Such a description includes changes in patient's personality, in his/her emotional sphere and behavior. In this regard, it is very important to analyze patient's premorbid personality traits. The cornerstone of schizophrenia research is the question about the role of stressful events, a long-term or intense psychological traumatization in the genesis of the disorder. It is assumed that schizophrenia is determined by increased vulnerability to stress, on the one hand, and exposure to stressful factors, on the other hand [3].

Gender and sex differences in the progression of schizophrenia and associated behavior changes are also interesting for researchers [6-8, 14]. Psychological differences between men and women have a neurobiological basis. Women can process information more stably and consistently and systematize it, while men have a greater ability for emotional-holistic perception and synthetic thinking [2]. The semantic coordinate system, concerning the phenomena of the outside world as well as one's own personality, is more conservative in women, and, therefore, it is more stable when an endogenous disorder appears. In women and men with schizophrenia, hospitalization rates differ. Women show lower rates of repeated hospitalization, they also stay in hospital for shorter periods of time [2]. According to the results of foreign researches, men with schizophrenia have more prominent negative symptoms and a higher level of social maladjustment. Thus, in female patients with schizophrenia there is a therapeutic pathomorphosis towards the alleviation of the disease, whereas men demonstrate a contrary tendency, especially over the past decade and a half. This is due to a wide range of factors, including the massive impacts of social stresses as well as 
the negative consequences of the so-called cultural trauma experienced by Russian society in the early 90s [4].

Starting to analyze gender differences in schizophrenia, it is necessary to explain why we use the word "gender", not "sex", when speaking of psychological characteristics. Psychologically, the differences between men and women are always conditioned by a combination of biological and sociocultural factors [5]. The term "gender" is intended to emphasize the fact that the biological features are not given to a person immediately, but are always refracted through the prism of individual development and upbringing, exist in the form of subjective experience. Stereotypic images of men and women had formed for ages, and they still apply to both genders irrespective of individual characteristics and age. These stereotypes extend to personality traits of men and women as well as to their behavioral patterns. There is a predetermined setting that competency is found in men more often than in women. Women are often characterized as more obedient, less objective and subject to external influence, less aggressive and competitive, they quickly flame up without any substantive reason. The typical image of a man is formed by a set of characteristics associated with socially unlimited manner of behavior, competency and rationality, activity and effectiveness. The typical image of a woman, in contrast, implies soft and communication skills, affection and emotional support.

We have conducted a study involving adults with a diagnosis of schizophrenia (F20). The purpose of the study is to study gender differences in the trigger mechanism for schizophrenia and their interrelations in the wider context of clinical symptoms. Besides, we were interested in how creativity and schizophrenia are interrelated.

\section{MATERIALS AND METHODS}

Detailed clinical conversation along with the life-line, sentence completion tests and genograms. Pathopsychological examination. Thematic Apperception Test (TAT). Analysis of medical records. Analysis of patients' verbal and graphic production. Dynamic observation

The study was carried out using the facilities of Moscow Regional Psychiatric Hospital No. 14 and psychological and social support service at this hospital. The participants of our research are the patients of a public non-profit regional clinic. It took us a year. The sample included 60 patients. The inclusion criteria: the diagnosis of schizophrenia (F20) verified by clinical examination (according to the diagnostic criteria of the ICD-10), age from 19 to 70, informed consent to participation in the study. Judging by the clinical picture of the disease, 56 patients had paranoid schizophrenia (F20.0), 1 had catatonic schizophrenia (F20.2), 1 had recurrent schizophrenia, 2 had schizophrenia associated with an oligophrenia-like defect. The exclusion criteria: prominent psychotic manifestations, disorganized behavior and formal attitude to the study.
We divided the subjects into two groups depending on the gender: 30 men and 30 women. Within each group, there were three subgroups depending on the stage of the disease: debut and disease duration of less than 5 years (40 patients), disease duration of 5-10 years ( 7 patients), disease duration of more than 10 years and the terminal phase (13 patients). We met each subject 3 or 4 times. One session was entirely devoted to a detailed clinical conversation. In our work, the emphasis is placed on the detailed clinical conversation, participant observation, collection of the anamnesis from relatives, doctors and hospital staff. The main criterion for analyzing gender differences in schizophrenia development was its trigger mechanism. We also assessed the contribution of a psychotraumatic situation to the development of the disease.

Gender differences in schizophrenia development were analyzed using the following criteria:

1. Premorbid background: characterological features, aggravating factors (bad habits, chronic somatic diseases).

2. The features of the social situation of development: the composition of parents' family, parenting style, aggravated heredity in collateral lines.

3 . The trigger for the onset of the disease.

4. Clinical picture: first episode symptoms, the theme of the delusion.

5. Social and sociopsychological factors in the course of the disease: social activity, marital status, presence of children. The severity of the disease course to a certain extent can be influenced by the current context that consists of the following elements: does the patient have or live in a family, meaning both spousal and parental relationships (in particular, the attitude of the close ones to the patient's state); does the patient have a job or any other socially oriented activity (in particular, preservation of professional skills in patients).

6. The features of compliance, including prognostic evaluation of the disease: critical attitude towards one's defective condition, orientation in one's own personality.

If the duration of the disease was from 5 to 10 years or more than 10 years the trigger mechanism was analyzed focusing mainly on the theme of the delusion. Clinical picture, first episode symptoms, the theme of the delusion - all of these reflect the past or the present psychotraumatic situation. As does the reduced delusion. Note, we are talking about the psychotraumatic situation, not the subjectively relevant situation. Psychological and social factors (job loss, jealousy-based conflicts, criminal conflicts, mobbing and bulling, family conflicts, relationship break-up, failure in personally important sphere, etc.) are reflected in the patient's experience and his/her verbal production. Information about psychological trauma in patients with the most recent first episode is confirmed by objective anamnesis.

The statistical analysis of the data was performed using the methods of descriptive statistics. This study was conducted on a relatively small sample, so in our case we cannot talk about statistically significant differences. 
Nevertheless, we find the results to be interest enough, and the obtained trends allow us to outline directions for further work.

All subjects gave their informed consent for inclusion before they participated in the study. The study was conducted in accordance with the Declaration of Helsinki, and the protocol was approved by the Ethics Committee of Psychological Institute of Russian Academy of Education (Project identification code 05-4/18. 2018 May 16)."

\section{RESULTS}

At this stage of the research we qualitatively analyzed the content of verbal and graphic production of patients that goes through the whole battery of tests. We were interested in whether the experience of psychotraumatic situation was repeated in each test. It is important that some psychotraumatic situation and/or theme is present in the majority of tests allowing to cross-check the results. A social or psychological factor that could become the psychological trauma (job loss, jealousy-based conflicts, criminal conflicts, mobbing and bulling, family conflicts, relationship break-up, failure in personally important sphere, etc.) was fixed in life-line. Analysis of medical records and expert opinion of the psychiatrist allow to put delusion into a particular thematic group: love relationship, damage, politics, etc. TAT and sentence completion tests confirm the presence of the theme in the patient's experience and its intensity. Here is the example of a story in accordance with the TAT table: "the woman is tired at work, at home; she needs a rest from the stress experienced from her husband who sent her out of the house", "no man married me, only raped", "I also need to arrange my love life, but only freaks stick to me". Here are the examples of phrases from the sentence completion test: "I am a bachelor now", "my company is tea, cigarettes and coffee", "my best friend was... there were no friends, let it be Roman". Classic pathopsychological examination was carried out as a support method for the doctor and verified the diagnosis. While it also reveals the theme of the delusion, even the reduced delusion. Dynamic observation confirms the stability of the theme in a particular patient.

According to the study, the majority of patients grew up in a two-parent family (62\% of men and $75 \%$ of women) with the permissive parenting style prevailing ( $81 \%$ of men and $75 \%$ of women). The trigger of the disorder in women is often a psychotraumatic situation associated with unhappy love or sexual experience: rape, attempted rape, "unhappy love" (56\% of cases). As for the factors aggravating premorbid background, eating disorders (37\% of cases) and suicidal behavior (31\% of cases) are the most common among women. The theme of the delusion: love $-18 \%$ of cases, damage and destruction $-25 \%$ of cases, politics $-6 \%$.

In the group of men, the trigger is also associated with a psychotrauma in the sphere of interpersonal relationships (38\% of cases). There are also such aggravating factors as antisocial behavior (18\% of cases) and alcohol and drug abuse (50\% of cases). As a rule, the theme of the delusion reflects the sociopsychological, cultural or even political situation which the patient was or is in. The delusion of love is noted in $6 \%$ of cases, the delusion of damage and destruction in $12 \%$ of cases. Comparing the men's group with the women's one, we've found out that love delusions are 3 times rarer, and delusions of damage and destruction are 2 times rarer in men. Politics is the theme of the delusion in $6 \%$ of men's cases, litigation - in $6 \%$, too. In the group of women, no delusion of litigation was observed during our research.

There is a clinical case from our experience. A male patient, 35 years old. The basic diagnosis: schizophrenia, the paranoid type. The father is an alcoholic. The patient says he was sociable and cheerful as a child, "had lots of friends". As a teenager he played hockey and football. At the age of 19 he was sentenced to 8 years of prison for a theft that he joined "in solidarity with his friends". He was released after 4 years in prison, got married and earned his living doing repairs. Alcohol abuse began at the age of 17 . In 2010, sleep disturbances appeared, it seemed to him that his friends communicated with him mentally. "I found out that I was threatened by a gang". At that time he was taken to a psychiatric hospital for the first time. He smokes a lot, suffers from severe bouts of cough. Quite indifferent to his physical health. Frank and outspoken when speaking about himself, which is not typical of men at his age. He says that after his release from prison he felt depressed and lonely. He also says that he drinks because when his workmates go drinking he feels particularly lonely and anxious. In the company "warmed up" by the alcohol this feeling leaves him for a while. He loves nature, dogs, picking mushrooms in the forest. He misses his wife and son. However, he can't quit drinking. Figure 1 presents a sample of the patient's graphic production.

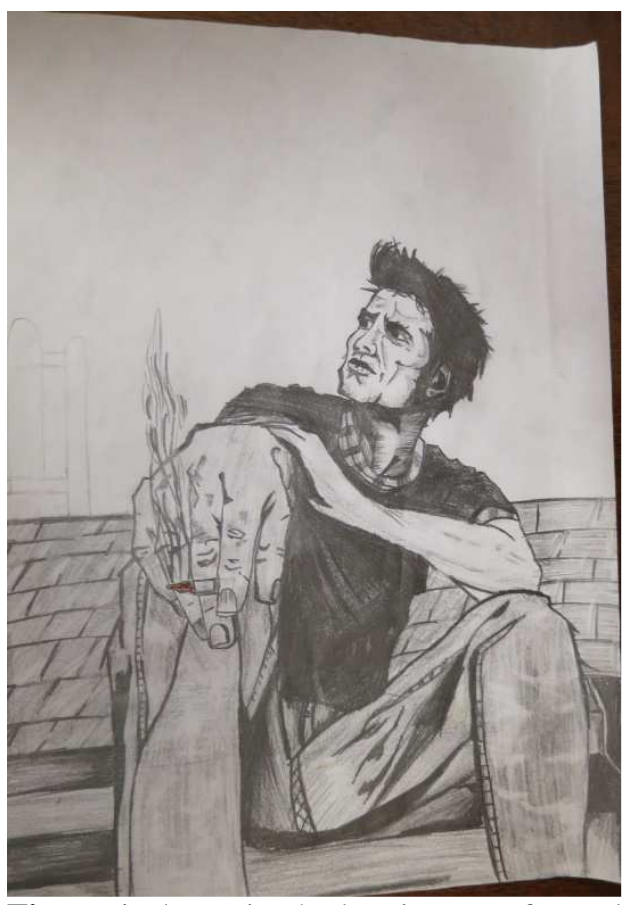

Figure 1 The patient's drawing on a free subject 
A woman of 56 years old. The basic diagnosis: paranoid schizophrenia. The additional diagnosis: irritable bowel syndrome. Her father died when the patient was 4, her mother - when she was 11 . She was brought up by her aunt who "used foul language". They lived in the Far East. At the age of 16 she moved to Moscow suburbs. While a teenager she liked to study, declaim poems (ex., by Alexander Blok). In the 90s she studied psychology in the Institute of Practical Psychology and Psychoanalysis, though she never worked in this field. During her study she had a job as a laboratory assistant in this institute. "Realized" that the laboratory manager "had fallen in love with her". She lived in the campus where, according to the patient, she experienced an attempted rape. It was at the same time that she started to have feeling that men are attracted to her: "They say they want to meet me; everybody wants me". She got married, got pregnant but lost her child. She attempted a suicide (tried to drown herself). Then she was admitted to a psychiatric clinic for the first time. She and her husband divorced; now she dates some man. She has been working in the service center as a secretary in the car repair shop. She likes to read, "learn new things", sometimes repeats during conversations: "Great deals do not tolerate minor acts". She is afraid of poverty, tries to make her dwelling "a comfort place". Although sexual delusions persist. Secretly in love with the renown Russian singer Valery Leontiev. She thinks he also has feelings about her and sends her "signs" at the concerts.

We assessed social and sociopsychological factors of the disease course, in particular, the kind of relationships with significant others, preservation of professional skills, social activity, compliance features. Active position is noted in $62 \%$ of women and only in $38 \%$ of men. Patients' ability to assess their disorder critically and to orient themselves in their own personalities is characterized by similar rates. $56 \%$ of women demonstrate a relatively critical attitude towards their defective condition. In men, this percentage is $37 \%$. At the time of the study, $56 \%$ of women are or were married, and $31 \%$ of them have children; among men, only $25 \%$ are or were married, and only $12 \%$ of them have children.

\section{DISCUSSION}

Social maladjustment in the formation of schizophrenia may be caused by a defect in the mechanisms processing visual, auditory and tactile information: such impairments reduce patients' ability to resist stress (Kobzova, 2012). Some kinds of stress, such as emotional and sexual abuse, relationship breakup, lack of job opportunities, are of particular subjective significance. Social gender stereotypes manifest themselves in the behavior associated with the attitudes towards mental and physical health. The traditional stereotypes don't allow men complain about being unhealthy and unsuccessful. Therefore, men are less motivated to seek professional help and tend to choose a maladaptive coping strategy, such as alcohol abuse. The society doesn't approve of such behavior in women, but tolerates it in men under certain circumstances, for example, as a reaction to social unsuccessfulness when a serious illness forms. The role of gender stereotypes is indirectly confirmed by the consistently high level of completed male suicides among the representatives of "masculine" professions: military personnel, law enforcement officers, etc. "If a man has made a decision, he must stick to it", says the social myth. We should note that the determinants of suicidal behavior in women are usually problems in interpersonal relationships, especially with the significant others, whereas in men these are conflicts and failures at work, the inability to support a family, poverty $[9,10]$. These data accord with the results of our research.

The hypothesis of interrelation between creativity and schizophrenia is supported by the results of the diagnostic work analysis. Classic pathopsychological examination methods, i.e. pictograms, the odd one out, object classification, notion similarity, projective drawing techniques, triggered slight actualization of latent properties of objects as a special way of thinking in patients. There is a clinical case of a 19-year old girl with literary talent. The basic diagnosis: schizophrenia, the paranoid type. The onset of the disease was triggered by a psychotraumatic situation related to bulling at school. Rich semantic and creativity in thinking (ex., "war" in the pictogram - a female figure with shadowed face and a torch). Creativity in thinking also revealed itself in the comment about the "jolly company" stimulus in the pictogram - a lot of smiles and a skeleton (she commented that "there was a skeleton in the company"). Being examined by the object classification method she chose the following groups: "five ways to scoop some water" (a truck, a saucepan, a water scoop, a ship, a sailor), "fragile and breakable" (a stand, an inkwell, a glass, a cart, a bookshelf, books, exercise books, a bottle, a cup). The girl uses quite complex grammatical structures in speech. According to the results of the Thematic Apperception Test, there is a qualitative creativity of the thinking process: producing fantasies about demonic immortal creatures, their habitats, "habits and life styles". During the examination she eagerly made a free drawing and depicted herself "in one of the Universes". "I am a cannibal in this Universe, I eat people. My name is Horia (from English "horror")", she commented.

Another clinical case of a 20-year old girl, a student of an art college. Teachers note her successes in studying. The basic diagnosis: paranoid schizophrenia. She was also a victim of bulling at school in the past. According to the results of the pathopsychological examination there are qualitative creativity in thinking and slight actualization of latent properties of objects. She sees similarities between a pillow and a skyscraper in "having been stuck with feathers; having form of rectangle or square; grid structure in both the material and the building". "Blood and kerosene give power to the lamp and us". Examples of the drawings and the comments by the girl during the pictogram task: "delicious dinner" - a hamburger and a window with stars. "Grief" - a butterfly with the broken wing. "Power" - a crown with the eye "to watch". Such 
images and comments are usually interpreted as slight actualization of latent properties of objects, disorders in motivation aspect of thinking. Creativity in thinking and emotional sphere was also found by the Thematic Apperception Test: "There is another world, like a dream, in which anything can exist - cats, witchers, dolls, mushrooms with spores that give rise to the mycelium". The idea of persecution is present: "big black dog that loves and hates at the same time". Figure 2 presents a sample of the patient's graphic production.

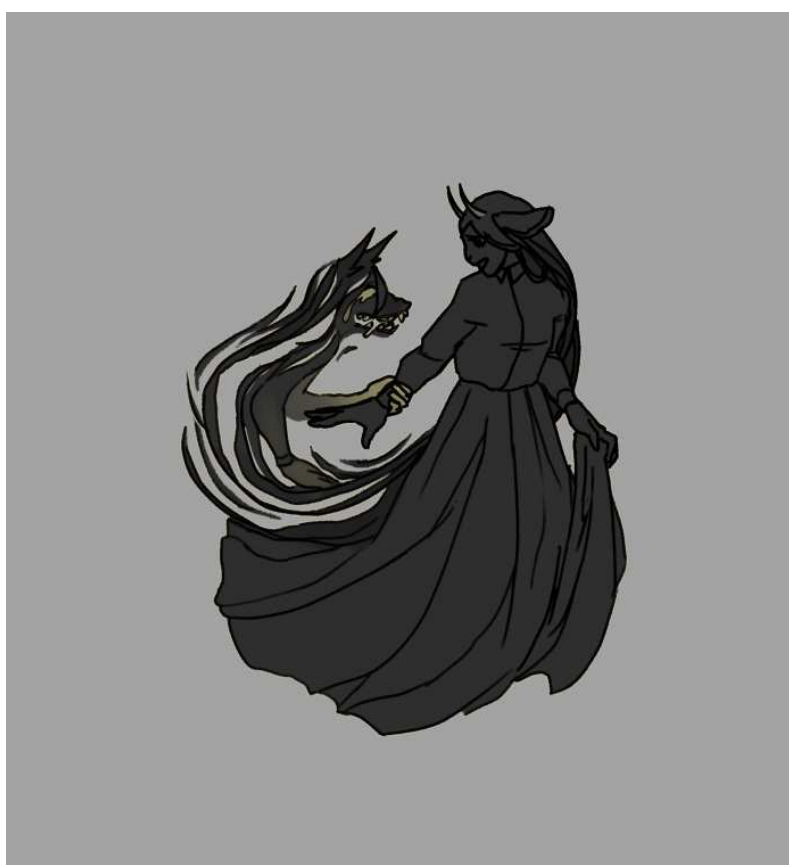

Figure 2

\section{CONCLUSIONS}

1. The role of psychotraumatic situation in the genesis of schizophrenia is significant in both women and men. Unhappy love and sexual experience can be a common important psychotraumatic factor. But the proportion of this factor is larger for women.

2. Among the dominant factors aggravating the premorbid background, eating disorders and suicidal behavior are typical of women whereas antisocial behavior and alcohol and drug abuse are typical of men.

3. The research has shown that the level of maladjustment caused by schizophrenia is lower in women than in men. Women demonstrate a more critical attitude towards their defective condition and orient themselves better in their own personalities than men. Due to the low threshold of biosocial adaptation, men react to stress, psychotraumatic situations, and deterioration of living conditions more acutely.

4. Considering the "gender paradox" associated with the (auto)aggression as well as the evidence that both hetero- and autoaggressive behavior are possible in schizophrenia $[9,10,13]$, during the treatment it is necessary to take into account the role of psychotraumatic situation in the genesis of the illness. Special attention should be paid to gender differences related to the psychotraumatic situation. It is recommended to take into account the character of psychological traumatization in the genesis of the patient's disorder when drawing up an individual rehabilitation program. Also the psychotraumatic situation is essential for drawing up a psychotherapeutic support program in individual work with patients.

\section{REFERENCES}

[1] S. Acar, X. Chen, N. Cayirdag, Schizophrenia and creativity: A meta- analytic review, Schizophr. Res. 195 (2018) 23-31. DOI: 10.1016/j. schres.2017.08.036

[2] A.Yu. Berezantsev, O.I. Mitrofanova, Gender, compliance and quality of life in patients with schizophrenia (analytical review), Russ. Psychiatric J. 1 (2009) 24-32.

[3] S.Ya. Bronin, Small psychiatry of a big city, BINOM, Moscow, 2018, 312 p. ISBN 978-5-95180543-0.

[4] M.M. Dudoladova, Value-rational practices in the postSoviet society as a result of a cultural trauma, Society. Environment. Development 4 (2014) 131-134.

[5] M.S. Egorova, O.V. Parshikova, M.A. Sitnikova, Sex differences in the Dark Triad traits, Psycholog. Res. (electr. Sci. J.) 39(8) (2015). Retrieved from: http://psystudy.ru/index.php/num/2015v8n39/1096egorova39.html

[6] M.P. Kobzova, Cognitive impairment and the problem of social maladjustment in schizophrenia, Psycholog. Res. (electr. Sci. J.) 22(2) (2012). Retrieved from: http://psystudy.ru/index.php/num/ 2012n2-22/650-kobzova22.html

[7] M. Leger, J.C. Neill, A systematic review comparingsex differencesin cognitive function inschizophreniaand in rodent models forschizophrenia, implications for improved therapeutic strategies, Neurosci Biobehav 68 (2016) 979-1000. DOI: 10.1016/j.neubiorev.2016.06.029. Retrieved from: https://www.ncbi.nlm.nih.gov/ pubmed $/ 27344000$

[8] R. Lewine, M. Martin, M. Hart, Sex versus gender differences in schizophrenia: The case for normal personality differences, Schizophr Res. 189 (2017) 57-60. DOI: $\quad$ 10.1016/j.schres.2017.02.015. Retrieved from: https://www.ncbi.nlm.nih.gov/ pubmed/28215470

[9] A. Mendrek, A. Mancini-Marie, Sex/gender differences in the brain and cognition in schizophrenia, Neurosci Biobehav Rev. 67 (2016) 57-78. DOI: 10.1016/j.neubiorev.2015.10.013. Retrieved from: https://www.ncbi.nlm.nih.gov/ pubmed/26743859 
[10] A.A. Pichikov, Yu.V. Popov, The "gender paradox" of suicidal behavior, The Bekhterev Revi. of Psychiatry and Med. Psychol. 2 (2015) 22-29.

[11] B.S. Polozhy, V.V. Vasilyev, Suicidal behavior among women, The Serbsky SSCSFP of the Ministry of Health and Social Development of Russia, Moscow, 2014, 325 p. ISBN: 978-3-846-55482-1.

[12] K.E. Sandsten, J. Nordgaard, J. Parnas, Creativity and psychosis, Ugeskr Laeger. 180(32) (2018), pii: V02180141.

[13] A.B. Shmukler, Modern approaches to the diagnosis of schizophrenia and schizophrenia spectrum disorders (DSM-5 conception), Gannushkin Psychiatry and Psychopharmacotherapy J. 5 (2013) 43-51.

[14] A.A. Tkachenko, G.E. Vvedensky, Primary diagnosis of schizophrenia in the accused with abnormal sexual behavior, The guidelines, The Serbsky SSCSFP of the Ministry of Health and Social Development of Russia, Moscow, 2013, 20 p. ISBN 978-5-86002128-0.

[15] A.A. Tkachenko, G.E. Vvedensky, N.V. Dvoryanchikov, Forensic sexology, BINOM, Moscow, 2014, 648 p. ISBN 978-5-9518-0619-2. 